\title{
Undoing the Colonial Gaze: Ambiguity in the Art of Brook Andrew
}

\section{Kate MacNeill}

The colonial archive's store of ethnographic images was a rich source for Australian Indigenous artists in the 1990s. The archive is dangerous territory as the images therein form an integral component of the project of colonialism itself. Indeed, it was an awareness of this power of the image and its role in the construction of "Aboriginality" that provided the motivation for artists such as Leah King-Smith, Fiona Foley and Gordon Bennett to return to the archive. ${ }^{1}$ One strategy they adopted in their appropriation of historical imagery was to recontextualise ethnographic photographs, and the circumstances of their production, within narratives of dispossession. King-Smith's series, Patterns of Connection (1992), in which nineteenth-century images of Aboriginal people in the collection of the State Library of Victoria are incorporated in photo-compositions, was one of the early examples of this form of corrective process.

At the same time as these artists were drawing on and re-presenting ethnographic images of Indigenous peoples, the museum and library sector was itself reviewing the manner in which the ethnographic photographs in their collections were displayed. Protocols were developed that acknowledged that the power of these photographs lay not only in the way they purported to document the past, but also in their contribution to the present. ${ }^{2}$ These protocols restricted the display of such photographs because of the distress the images may cause to some Indigenous viewers. ${ }^{3}$ The display of the photographs was also restricted because of the agency that these images retained in the continuing construction of "Aboriginality" through the reenactment of the colonial gaze.

Once the ethnographic image had been appropriated or, I should say, reclaimed by Indigenous artists, the agency of the original photograph tended to be overlooked in the reception of the 
new work. In this article I examine a very specific use of ethnographic images in two works by the Wiradjuri artist Brook Andrew. I suggest that Andrew's work restages and disrupts the processes by which imaging itself constructs "Aboriginality" and the "other." In this sense, his work both recognises and subverts the role of the image in the performative processes of identity construction. His new works might then be understood as an example of that which Judith Butler suggests is the way performative repetition of "identity" can be employed as a destabilising political strategy. ${ }^{5}$

Homi Bhabha, in theorising the political agency of the colonised subject, adapts a theory of identity performance to "picturing". The imperative to picture and to take control of that picturing is, for him, a crucial aspect of political struggle: the colonised subject's political demand must include "a struggle for the historical and ethical right to signify." 6 However, Bhabha and others have noted that, although imaging itself plays a part in the construction and constant reiteration of "identity," care is needed to ensure that the criticality of the activity is maintained. In Nation and Narration, Bhabha addressed this issue when he cautioned that "in the heat of political argument the 'doubling' of the sign can often be stilled."

Some years after King-Smith commenced her project with the State Library of Victoria, Brook Andrew also turned to the archive of ethnographic imagery. Between 1996 and 1998 he found there a number of photographs, which he then incorporated into three works: the well known Sexy and Dangerous (1996) and two lesser known works: I SPLIT YOUR GAZE (1997) and NGAJUU NGAAY NGINDUUGIRR (I see you) (1998). It is these works that I examine in this article. The political agency that I attribute to I SPLIT YOUR GAZE and NGAJUU NGAAY NGINDUUGIRR derives from Andrew's attack on the ethnographic photographs on their own terms as visual weapons of colonialism. The process of subject construction performed by the ethnographic image is restaged by these works, but in the new images it is principally the viewer's sense of self that is invoked, through the work at first inviting the colonial gaze and then refusing it. It is this direct challenge to the viewer that might explain responses that describe the viewing of Andrew's work as particularly unsettling. Anne Loxley has written of how Andrew's work makes things "tricky to the viewer who may be destabilised by contrary messages lurking within the beauty;" Warren Coatsworth wrote of the "anxiety" that might be experienced when looking at a work of Andrew's; and Hannah Fink described her experience of viewing a work as "disturbing." 8

These responses to Andrew's art are consistent with the emphasis that it places on the selfidentification of the viewer. Not surprisingly, readings of Andrew's art as an expression of self are not readily available and are rarely attempted. Andrew has consistently made a point of resisting interpretation of his work as an expression of self, or indeed as an expression of a 
particular view. In a rare exception, and even here with a twist, he addressed the expectations that are placed on him and on his work. Quoted in the catalogue essay for devil (2000), Andrew described devil as being his first self-portrait, which was produced in response to constant interrogation about how he negotiates his own cultural and political identities. ${ }^{9}$ If indeed the various aspects of Andrew's identity had required "resolution," it would, as Andrew explains in devil, send him quite mad:

I am comfortable with who I am, it is others that try to create a problem for me. devil is a direct response to this idea and that is why I have depicted myself in a psychiatric cell - people often comment on how they think my multi-identity should make me crazy! but this is about them, not me. ${ }^{10}$

Devil then might be thought of not as a self-portrait, but as a portrait of Andrew as seen by others; specifically those who regard aspects of his identity as being in competition. While devil might depict a decentred self, Andrew's comments reject any suggestion that this image expresses a desire for a unified identity on his part. His statement "this is about them, not me" demonstrates the way in which an identity is imposed upon him by others, and his view that this reveals more about them than him.

Andrew's biography is relevant to his art making, I suggest, only insofar as it is his lived experiences of attempts by others to impose identities upon him that have informed his work. The two images that I examine might be regarded as part of a corrective project - but not one that makes visible the invisible subjects of Australian history. Rather, I argue that in these works Brook Andrew is challenging the process of signification itself, and its role in the construction of the colonial subject. He achieves this by shifting the emphasis away from representational aspects of the ethnographic photograph and by placing responsibility on the viewer to resist the viewing position of the coloniser. Despite obvious similarities with the subject-matter of King-Smith and Bennett's art, it is this strategic, destabilising aspect of Andrew's work that invites direct comparison with particular feminist art projects of the early 1980s. In Australia, Catriona Moore described these projects as emphasising the instability of gender categories rather than attempting to recover "an authentic feminine voice."11

From the 1970s onwards, art has been one site in which the women's movement, black activism and gay pride have, at different times, adopted a political strategy of visibility and self-representation, a project partly described by the terms "identity art" and the "culture wars." As Marcia Langton observed, in her much-cited writing on Aboriginal representation and film, a growing awareness of the manner in which Indigenous peoples are represented in popular culture in Australia has led to increased efforts on their part to take control of this process. ${ }^{12}$ Langton cautioned against Indigenous peoples seeking complete control of Indigenous 
imaging, implying as it does, that there is a "right" way to be Aboriginal or that there can be "true" representations of "Aboriginality." Such inferences, she said, ignore the extensive cultural variation among Indigenous peoples. ${ }^{13}$ Both Langton and Bhabha alert us to the fact that assertion of the "right to signify" implicitly reinforces a presumption that there is equivalence between an image and an identity category, which in the case of Andrew's works is that of the "Aboriginal".

Andrew is the child of an Indigenous mother and non-Indigenous father. His work could all too easily be seen in the same manner as Ian McLean has approached the art of Gordon Bennett; as being a reflection of the self as the hybrid, and hence split, postcolonial subject, and his work understood as a quest for unity. ${ }^{14}$ However, as I have indicated, this approach would be totally at odds with Andrew's intentions for his work. More importantly it would overlook particular visual aspects of his work which I will demonstrate resist an interpretation based on any self-revelation of the artist - but instead more directly implicate the viewer. In making this argument I suggest that Bhabha's concept of hybridity remains productive in the specific sense that Bhabha proposed an art of cultural hybridisation as being an art that would take what is "unresolved, ambivalent, even antagonistic, and perform[s] it in the work" in a manner that ensures that questions of identity remain open. ${ }^{15}$

In his 1993 Whitney Biennial catalogue essay Bhabha described the end of the twentieth century as a time in which we might "find ourselves in the moment of transit ... [when] there is a sense of disorientation ... an exploratory, restless movement." ${ }^{16}$ Emphasising the multiplicity of subject positions that any one person might inhabit, Bhabha described an inbetween space as the unfamiliar contingent territory between designations of identity. In other words, the effect of hybridity in the day-to-day is that of living "in the unhomely world," an out-of-register world. I suggest that Andrew's work does not represent hybridity, but that it performs hybridity, providing the viewer with a form of liminal experience. For it is the ability of Andrew's work to bring the viewer into an in-between space that, I suggest, makes these images particularly effective forms of cultural activism.

Andrew's intention in his 1997 work I SPLIT YOUR GAZE was, literally, to "split the colonial gaze" [fig. 1]. ${ }^{17}$ This was achieved by splitting the object of the gaze down the middle. Using an anthropological photograph, the face was halved and the left and right sides switched and placed against the border of the work, creating a white space in between. ${ }^{18}$ The image structure that is achieved through this manipulation establishes a persistent disruption for the viewer: the source photograph may come from the colonial archive, but Andrew's reworking of it denies the viewer the opportunity to further objectify the subject of the image, ensuring that the viewer must look at it anew. 
This encounter with the unfamiliar denies the viewer the power to colonise the subject of the image and invokes a particular form of "black signifying." In conversation with W.J.T. Mitchell, Homi Bhabha agreed with the description of a practice of "black signifying" as "a kind of splitting of the language of authority, and returning that language in a just-slightlyaltered state." 19 Bhabha explained the political potential of this strategy when he added that this altered state "often destroys the calculations of the empowered, and allows the disempowered to calculate the strategies by which they are oppressed and use that knowledge in structuring resistance." 20 Bhabha's splitting does not function within a binary of whole/split or reconciled/apart and Andrew's image has not been split to invoke a split self. It is more appropriate to regard the image as enacting Bhabha's concept of splitting as a strategy, a strategy that creates a space where "the work of signification voids the act of meaning.", other words, the image no longer has a direct equivalence with a particular identity, in this case, the all-too-familiar colonial subject.

When I SPLIT YOUR GAZE was shown at the National Gallery of Australia in "Re-Take," an exhibition of Indigenous photography, the image was described as "a metaphor for the dyslexia of the end of the twentieth century." 22 It was further noted that "on this image the eye can never rest." ${ }^{, 23}$ I therefore suggest that the realisation of the work also functions on a less metaphoric level. In the moment of viewing it can be thought of as an experience of a form of dyslexia: one in which elements of the work are observed, but do not make sense as a whole. The moment can be understood as an undoing of the colonial gaze.

The inability of the viewer to reconcile elements of I SPLIT YOUR GAZE is similar to that which Mitchell described as being produced by "multistable" images. He used this term for a range of pictures in which there is an ambiguity of the referent, where "contrary or simply different readings" co-exist in the single image. ${ }^{24}$ This led Mitchell to propose that the multistable image is in fact a "device for educing self-knowledge, a kind of mirror for the beholder," and that the viewer's dialogue with these images is inevitably "embedded in specific discourses, disciplines, and regimes of knowledge." 25 In fact, I SPLIT YOUR GAZE shares many characteristics of one of the best-known multistable images, Rubin's Vase [fig. $2]{ }^{26}$ Rubin's Vase offers the viewer a central panel, in which can be seen as a vase, or alternatively the two side panels, which are profiles of the same face, and is frequently discussed in terms of its demonstration of gestalt theories of visual perception. Ann Marie Barry used this image to illustrate our automatic desire to complete an unfinished image, and described the impact of Rubin's Vase on the viewer as ambiguous, an outcome that results from "the forces for segregation and cohesion" in the work being equivalent. ${ }^{27}$ While Barry drew on gestalt theory and emphasised the operations of the optical system, the contribution 
that Mitchell and others made to understanding this process of meaning-making has been to emphasise the role played by the viewer's expectations, memory and reasoning. In practice this means that when we look at an image of a person we receive bits of visual information, which we then piece together, primarily based on a stereotype, to produce "an identity." Regardless of whether the acquisition of this form of visual intelligence occurs automatically in the early stages of life, or arises through experience, both theories acknowledge the compulsion to complete an image as an identity.

Once the lessons of Rubin's Vase are applied to the work I SPLIT YOUR GAZE, we can understand how this image is able to simulate an actual experience of visual dyslexia for the viewer - an experience in which elements of the work are recognised, but the work is not able to be seen as a whole. Alex Gawronski had suggested that the work forces the viewer to "stare blankly through the image," but I suggest that this is an inadequate explanation. ${ }^{28}$ Just as Barry observed in Rubin's Vase, competing forces for segregation and cohesion within the image ensure that the viewer is incapable of staring blankly, as their eyes will attempt to see what they believe they should be able to see, based on the work's various visual cues.

In Andrew's I SPLIT YOUR GAZE, the use of an actual photograph and the direct address of the viewer achieved by the split face further thwart this entrenched process of visual comprehension. The direct address ensures that Andrew's image varies in another important respect from Rubin's Vase, namely that the white space between the two halves of the face takes a form that is not identifiable as any particular thing. ${ }^{29}$ The absence of the (Rubin's) vase ensures that the work does not fall into a simple binary of black-and-white. By refusing the viewer's gaze the ability to switch between two alternately recognisable "identities," the critical agency of the image is reinforced. Given the iconic nature of Rubin's Vase, and its familiarity to many viewers of Andrew's work, it is arguably these modifications that confuse the viewer's expectations of it, and reinforce the image's criticality. What might start out as subversive images lose their agency over time, as familiarity with the image ensures that it too may be "stilled."

The feelings of unease, anxiety and disorientation that have been reported when viewing Andrew's work might, in the case of I SPLIT YOUR GAZE, be explained by the inability of the viewer to draw on "existing regimes of knowledge" when trying to read the image. Not only does the image cause the viewer to reflect on the process of looking, but they are also offered a way of looking differently, a way in which image and Aboriginal identity are not equated. Andrew reveals the pervasive way in which identity and imaging are internalised when he tells a story of his own experience as an eighteen-year-old. It describes his response to seeing a fair-skinned woman who was also a student in the Aboriginal bridging course that Andrew 
attended at the University of Technology Sydney. Upon walking into the room he thought, "she's not Aboriginal." He continued:

Then I realised my own racism, I realised that where I come from, in my community they know who I am, but that we also have our own ideas about Aboriginality which are still informed by stereotyped modes of racism - that was a real shock for me. ${ }^{30}$

In I SPLIT YOUR GAZE then, Andrew attacks the stereotype at its source - the semiotic structure of the image. Through destabilising the technologies of perception, the image subverts the authority of the gaze in the performative construction of the subject, and the making of "Aboriginal" identity. Much of the interpretation that I have offered has not made explicit that the image is that of an Indigenous man, an outcome that is entirely consistent with Andrew's project. As he observed:

When he's cut down the middle, and swapped over too, his form as an Aboriginal man is split - he doesn't even look like an Aboriginal ... so it's not what he looks like anymore. $^{31}$

In NGAJUU NGAAY NGINDUUGIRR [fig. 3] Andrew once again sourced an image from the ethnographic archive. ${ }^{32}$ Rather than split the image this time Andrew presented a partial image; the work emphasised the man's eyes, and in fact the image consisted of little else. The interference with the gaze on this occasion emphasised the technologies of looking. NGAJUU NGAAY NGINDUUGIRR first appeared in the exhibition "bLAK bABE(z) and kWEER kAT(z)," together with the work of the artist Rea, at Gitte Weise Gallery, Sydney, in 1998. It was later exhibited at the 2000 Biennale of Contemporary Art in Noumea. As an installation, the work enabled the viewer to move between the elements of the piece. ${ }^{33}$ The neon Wiradjuri text, NGAJUU NGAAY NGINDUUGIRR, is fixed to the wall with an image of a man's face suspended some metres in front of it. When the neon is reflected against the image, the text appears across one of the eyes. The image of the eyes is on a transparent perspex surface. On the one hand, a viewer can look into the eyes, and through to the neon text. On the other hand, if standing between the image and the neon, the viewer can look outward through the eyes, with the neon behind and, in that position, can be looked at by other viewers. The viewer is invited to enter the space of the work and to participate in the experience of seeing and being seen.

The work once again reflects Andrew's project of cultural activism, one that does not seek to picture an actual alternative identity, to redefine Aboriginality, but rather to disrupt the act of viewing. On this occasion Andrew makes transparent the role that acts of looking play in the construction of identity: 
It's really about looking at someone, it's about discrimination. Basically about the act of looking ... but it is about the colonial gaze as well ... At the end of the day for me, it's about the act of looking ... And that can inform racism, sexism - it can be anything. I wanted to broaden the whole identity issue. ${ }^{34}$

In this quote, Andrew explicitly addresses the way in which looking is one means of colonising the subject, not merely the raced subject, but also the gendered. The look positions the subject and, in Andrew's experience, wants to impose a unity on that subject. It is a perception of the irreconcilable nature of multiple identities that might, at times, frustrate those inclined to attempt reductive readings of his work. Warren Coatsworth seemed to attempt such a reading when he described the work as providing the viewer with "a powerful insight into the ways in which existing binary structures effectively marginalise those with fluid cross-cultural identities - the so-called 'in-between." ",35

As Andrew has emphasised on numerous occasions, he does not regard his life as being spent in any "in-between." When Coatsworth reported on his own experience of "feelings of anxiety ... provoked by attempting to reconcile the disjunction between text and visual sign," he articulated Mitchell's assertion of the way in which the multistable image functions as a device for self-knowledge. In this case the instability of the image is created by the multiple viewing positions that are offered, positions that produce an "in-between space" in the work, a space in which the viewer is unable to reconcile its apparently disparate elements. Coatsworth's observation, then, is not an attempt to impose a biographical reading of the work, one that would view the work as a reflection of Andrew's own life. The feelings of anxiety expressed when viewing NGAJUU NGAAY NGINDUUGIRR, feelings Coatsworth attributed to his inability to resolve "the work's internal tensions," attest to the effectiveness of the work in providing an interstitial experience. Such an experience, Bhabha argued, can take "you 'beyond' yourself in order to return, in a spirit of revision and reconstruction., 36

Both NGAJUU NGAAY NGINDUUGIRR and I SPLIT YOUR GAZE clearly reference the role of the gaze in the process of subject construction and there are obvious continuities with the 1980s work of Barbara Kruger. ${ }^{37}$ Laura Mulvey's theory of the gaze proved to be an effective critique of patriarchal power for feminist artists in the 1980s such as Kruger and, in Australia, Sandy Edwards and Anne Zahalka. ${ }^{38}$ The gaze is understood as both structured by and contributing to relationships of power. In Kruger's work of the early 1980s the gaze was frequently "returned" in what she has described as "a series of attempts to ruin certain representations and to welcome the female spectator into the audiences of men." ${ }^{39}$ The work of Kruger's that most explicitly addresses the issue of the gaze, Untitled (Your Gaze Hits the Side of my Face) (1981) [fig. 4], uses text to speak back to the source of the gaze. The image 
is identified by Craig Owens as having been sourced from a 1950s photo-annual image of a statue of a female bust. ${ }^{40}$ Kruger has added the text "your gaze hits the side of my face" down the left hand side of the image.

The ambiguity in Kruger's work is primarily achieved through her use of pronouns which operate to shift meaning, the "I" and "you" of the works giving rise to an ambiguity as to speaking positions. In a less prominent way, the pronouns in Andrew's title, I SPLIT YOUR GAZE, serve the same function, as does the text NGAJUU NGAAY NGINDUUGIRR for Wiradjuri speakers, from which it translates as "I see you." 41 Language is used extensively in Kruger's work, often in the form of a statement that explains or complements the image and she has referred to this use of language as a response to the "muteness" of the image that arises "when it is stilled." 42 Kruger draws on language out of concern that the image is mute; her language activates the ambiguity in the work. In contrast, Andrew's use of text in NGAJUU NGAAY NGINDUUGIRR is cryptic, and cannot be read as a language. For most viewers it will function as one more source of inscrutability, one that renders many viewers momentarily "illiterate".

The Wiradjuri language in NGAJUU NGAAY NGINDUUGIRR and, in other work, Andrew's incorporation of Chinese, Hindi and Japanese, serve as reminders that looking is not a mechanism for understanding - most viewers will see the language but are left to puzzle over its meaning. As Gawronski observes, this "language blinds to the wholeness of comprehension." 43 For the viewer literate only in English, some of Andrew's work can be read for meaning, but the Wiradjuri, Japanese or Hindi remain inaccessible as forms of literal expression, denying the viewer the chance to impose a unifying meaning on the work.

NGAJUU NGAAY NGINDUUGIRR and I SPLIT YOUR GAZE, in different ways, both refuse to speak with any authority: they do not presume to represent the artist in a form of selfportraiture, nor do they speak for the artist as a form of self-revelation. Andrew has used the inherent power of the image, the power that made ethnographic photographs such effective weapons of colonialism, to shift the onus of representation away from the artist and place it with the viewer. Specifically, the viewer cannot reconcile what they see with what they think they know, and may experience a sense of disorientation when unable to equate an image with a preconceived, Aboriginal identity.

I am not suggesting that Andrew's images represent a more effective anti-colonial critique than those of other artists. I have asserted that they function in very different ways. Andrew's target is the way in which the colonial legacy is implicated in the everyday relationship between ways of seeing and identity construction. The "multistable" aspect of these images is 
the means whereby they resist the stilling effect of identity categories that Bhabha cautions may arise through a political activity of imaging the self. It is also the means by which the viewing subject is destabilised. In this moment of disorientation, in this actual experience of hybridity, an opportunity is presented that provides the viewer with a different way of seeing.

Kate MacNeill, School of Art History, Cinema, Classics and Archaeology, University of Melbourne.

\footnotetext{
${ }^{1}$ See King-Smith in her artist's statement in Patterns of Connection (Melbourne: Victorian Centre for Photography, 1992) unpaginated. The exhibition was held in April-May 1992; Fiona Foley drew on ethnographic images in her Native Blood series (1994) and in later work included them in her Wild Times Call series (2001-2). Gordon Bennett identified the role of anthropology and ethnography in constructing concepts of Aboriginality in the present, in Ian McLean and Gordon Bennett, The Art of Gordon Bennett, (Sydney: Craftsman House, G+B Arts International, 1996) 31-4. Bennett's works Self-portrait (Gone Primitive) (1992) and Self-portrait (Vessel) (1992) both incorporate references to these disciplines. In the second of these two works, Bennett, like Andrew, uses a version of Rubin's Vase.Bennett's work, however, features his own profile.

${ }^{2}$ E.g. Aboriginal and Torres Strait Islander Protocols for Libraries, Archives and Information Services, comp. Alex Byrne, Alana Garwood, Heather Moorcroft and Alan Barnes, endorsed at the Aboriginal and Torres Strait Islander Library and Information Resource Network Conferences, December 1994 and September 1995, and at the First Roundtable on Library and Archives Collections and Services of Relevance to Aboriginal and Torres Strait Islander People, May 1995. Available online at http://alia.org.au/policies/atsi.protocols.html.

${ }^{3}$ In many Indigenous communities the display of images of deceased persons is not permitted, and there may also be material in photographs that is not suitable for general viewing for cultural reasons.

${ }^{4}$ Recent aesthetic theories of political agency have focused on interconnectedness rather than the deconstruction of identity, e.g. Jill Bennett's analysis of the critical potential of affect in Empathic Visions: Affect, Trauma, and Contemporary Art, (Stanford, Calif.: StanfordUP, 2005). However Bhabha's theorising of postcolonial artistic agency was produced contemporaneously with Andrew's 1990s' art-works, which reflect the concerns of identity politics. For my purposes here, therefore, Bhahba's theory offers a more productive line of enquiry.

${ }^{5}$ Judith Butler, Bodies that Matter: on the Discursive Limits of "Sex", (London \& NY: Routledge, 1993).

${ }^{6}$ Homi Bhabha, "Freedom's Basis in the Indeterminate," October - The Identity in Question, 61 (Summer 1992) 46-57.

${ }^{7}$ Homi Bhabha, Nation and Narration, (London \& NY: Routledge, 1993) 3.
} 
${ }^{8}$ Anne Loxley, “The Battles Continue: Brook Andrew," Colour Power: Aboriginal Art Post 1984, ed. Judith Ryan, (Melbourne: National Gallery of Victoria, 2004) 143; Warren Coatsworth, "brook andrew and rea, bLAK bABE(z) and kWEER kAT(z)," Eyeline, 36 (Autumn/Winter 1998) 38; Hannah Fink, “Cracking Up” Beyond Myth, ex. cat., (Melbourne: Gabrielle Pizzi Gallery 1999) 13.

${ }^{9}$ Maud Page, Polemics, ex. cat., (Melbourne: Gallery Gabrielle Pizzi, 2000).

${ }^{10}$ Ibid, unpaginated.

${ }^{11}$ Catriona Moore, Indecent Exposures, Twenty Years of Australian Feminist Photography, (Sydney: Allen \& Unwin, 1994) 111.

${ }^{12}$ Marcia Langton, Well I Heard it on the Radio and I Saw it on the Television.... (Sydney: Australian Film Commission, 1993) 9.

${ }^{13}$ Ibid, 27.

${ }^{14}$ Ian McLean's writing on the work of Gordon Bennett has at times suggested that this is Bennett's principal motivation. See Ian McLean, White Aborigines: Identity Politics in Australian Art, (Cambridge \& NY: Cambridge UP, 1998) 138-47. More recently, McLean has reflected on his past writing and noted that he may have been placing the "burden of representation" on Bennett: "The most important lesson I have learnt in writing and speaking about Bennett's work over the previous five years is not to pass on to him that burden of representation ... of not, for example, reading his work in too autobiographical a fashion, as if here speaks the Aborigine of his identity problems, as if the problems he pictures are the Aboriginal ones. Yet I have, in the past, invested in the argument that Bennett's work pictures all the conundrums and aporias of Australian identity." Hancock Lecture, University of Sydney, 11 November 1998, republished as "Post Colonial: Return to Sender," Australian Humanities Review 12 (December 1998), online journal $<$ http://www.lib.latrobe.edu.au/AHR/archive/Issue-December-1998/mclean2.html > ${ }^{15}$ Homi Bhabha, "Halfway House (Art of Cultural Hybridization)," Artforum International, 35.9 (May 1997)11, 12, 125. Bhabha has elsewhere argued for ambiguity and ambivalence in fiction and sundering and splitting in art as effective forms of political intervention, in The Location of Culture, (London \& NY: Routledge, 2004) 1-27.

${ }^{16}$ Homi Bhabha, "Beyond the Pale: Art in the Age of Multicultural Translation," Elisabeth Sussman et al., 1993 Biennial Exhibition, ex. cat., (NY: Whitney Museum of Art, 1993) 62.

${ }^{17}$ Brook Andrew, Interview with author, Melbourne, 13 July 2004.

${ }^{18}$ Andrew refers to the image as being that of an Aboriginal man from New South Wales, sourced from the Mitchell Library: and, in "Seeing Black", Gawronski identifies the man as Cunningham:Alex Gawronski, "Brook Andrew: Seeing Black," Globe 10.

www.arts.monash.edu.au/visarts/globe/issue10/batxt.html) [accessed 11 July 2004]. This site has recently been decommissioned.

19 “Translator Translated," Artforum International, 33.7 (March 1995) 80-3, 110, 114, 118, 119.

${ }^{20}$ Ibid.

${ }^{21}$ Bhabha, The Location of Culture: 188.

${ }^{22}$ Lisa Havilah, "Brook Andrew”, August 1998 at www.nga.gov.au/Retake/artists/00000000.htm [accessed 13 October 2004]. This online publication contained material that was not included in the 
exhibition catalogue: Re-Take: Contemporary Aboriginal and Torres Strait Islander Photography, ex. cat. (Canberra: National Gallery of Australia, 1998-9).

${ }^{23}$ Ibid.

${ }^{24}$ Examples provided include the "duck-rabbit" and "my wife or my mother-in-law", both of which present the viewer with alternative pictures within the one image, W.J.T. Mitchell, Picture Theory: Essays on Verbal and Visual Representation, (Chicago: University of Chicago Press, 1994) 45-8. ${ }^{25}$ Ibid, 48.

${ }^{26}$ In his 1994 treatment of multistable images Mitchell makes no reference to Rubin's Vase but in his more recent work, What do Pictures Want? The Lives and Loves of Images, (London \& Chicago: The University of Chicago P, 2005), he refers to what he calls the "classic multistable image of the one vase/two faces," 210-11.

${ }^{27}$ Ann Marie Barry, Visual Intelligence: Perception, Image, and Manipulation in Visual Communication, (Albany: State University of NY P, 1997) 51.

${ }^{28}$ Gawronski, "Brook Andrew: Seeing Black,": 38.

${ }^{29} \mathrm{I}$ am grateful to Terry Smith for his comment on this aspect of the work when an earlier version of this paper was presented to the AAANZ conference, Sydney, December 2005.

${ }^{30}$ Brook Andrew, Interview with author.

${ }^{31}$ Ibid.

${ }^{32}$ Andrew identifies this image as being of the same man as the one in the source photograph for $I$ SPLIT YOUR GAZE, however this time Andrew used a different photograph.

${ }^{33}$ The description of the work is drawn from Andrew's discussion of the exhibition in Chris Chapman, "Never Make Decisions Based on Fear: The Work and Ideas of Brook Andrew," 40.3, Art and Australia, (Autumn 2003): 446-53.

${ }^{34}$ Brook Andrew, interview with author.

${ }^{35}$ Coatsworth, "brook andrew and rea":38.

${ }^{36}$ Homi Bhabha, "Beyond the Pale": 65.

${ }^{37}$ These continuities are referred to by Marcia Langton in her essay "High Excellent Technical Flavour," ex. cat. Hope \& Peace, (Melbourne: Gallery Gabrielle Pizzi; Sydney: Stills Gallery, Adelaide: Greenaway Gallery, 2005).

${ }^{38}$ Moore, Indecent Exposures: 105-11.

${ }^{39}$ Quoted in Helen Hills, "Commonplaces: The Woman in the Street: Text and Gender in the Work of Jenny Holzer and Barbara Kruger," Language and Gender, Interdisciplinary Perspectives, ed. Sara Mills (Harlow: Longman, 1995) 241.

${ }^{40}$ In Mitchell's What do Pictures Want?, he describes the face in this work as being of indeterminate gender: 45 . However in more contemporaneous readings of this image the face is presumed to be female and the image read within a binary, though not essentialising, framing of gender. See, e.g. Craig Owens, "The Discourse of Others: Feminists and Postmodernism", Beyond RecognitionRepresentation, Power and Culture, eds. Scott Bryson, Barbara Kruger, Lynne Tillman and Jane Weinstock (Berkeley, LA, Oxford: University of California P, 1988) 183-4 where Owens refers to the image as having been "culled from a '50s photo-annual of a female bust" and in Kate Linker, Love for Sale, The Words and Pictures of Barbara Kruger, (NY: Harry N. Abrams, Inc., Publishers, 1990) 62. 
The Australian and New Zealand Journal of Art, Vol. 6, no. 2, 2006 and Vol. 7, no. 1, 2007.

This is not to say that the image cannot be read as androgynous. If it is more likely to be seen in this way in 2005 this may reflect the profound influence of Butler's work on sex and performativity in Gender Trouble and Bodies that Matter, in the intervening years, and no doubt the viewer's own expectations.

${ }^{41}$ As told to Chapman, "Never Make Decisions Based on Fear": 450.

${ }^{42}$ Karen Raney, "Barbara Kruger," Art in Question, (London and NY: Continuum, 2003) 117.

${ }^{43}$ Gawronski, "Brook Andrew: Seeing Black." 


\section{University Library}

- MIN E R VA A gateway to Melbourne's research publications

Minerva Access is the Institutional Repository of The University of Melbourne

Author/s:

MacNeill, Kate

Title:

Undoing the colonial gaze: ambiguity in the art of Brook Andrew

Date:

2006/2007

Citation:

MacNeill, K. (2006/2007). Undoing the colonial gaze: ambiguity in the art of Brook Andrew.

The Australian and New Zealand Journal of Art, 6/7(2/1), 179-194.

Publication Status:

Published

Persistent Link:

http://hdl.handle.net/11343/34888

File Description:

Undoing the colonial gaze: ambiguity in the art of Brook Andrew 


\section{University Library}

\section{- M M I N E R VA A gateway to Melbourne's research publications}

Minerva Access is the Institutional Repository of The University of Melbourne

Author/s:

MacNeill, K

Title:

Undoing the Colonial Gaze: Ambiguity in the Art of Brook Andrew

Date:

2006-01

Citation:

MacNeill, K. (2006). Undoing the Colonial Gaze: Ambiguity in the Art of Brook Andrew. Australian and New Zealand Journal of Art, 7 (1), pp.179-194. https:// doi.org/10.1080/14434318.2006.11432769.

Persistent Link:

http://hdl.handle.net/11343/29128 